\title{
Contained: why it's better to display some products without a package
}

\author{
Courtney Szocs ${ }^{1} \cdot$ Sara Williamson $^{2} \cdot$ Adam Mills $^{3}$ \\ Received: 29 May 2020 / Accepted: 29 June 2021 / Published online: 27 August 2021 \\ (C) Academy of Marketing Science 2021, corrected publication 2022
}

\begin{abstract}
Across varying marketplace contexts (e.g., grocery stores, restaurants, e-commerce) managers display products with and without packaging, seemingly arbitrarily. Does displaying a product packaged as opposed to unpackaged influence consumers' product responses? Six controlled experiments and an Instagram study address this question. We focus primarily on food products but show our results extend to non-food products that are natural (i.e., originate from plants, animals, or humans). We propose that, in addition to its physical function, packaging acts as a symbolic barrier that separates the product from nature, decreasing perceived product naturalness and leading to less favorable product responses. Consistent with our theorizing, the negative effects of packaging attenuate when product information or retail signage highlights the product's connection to nature and are contingent on the importance of product naturalness. Our findings have implications for strategic use of packaging in physical and digital merchandising and sustainability initiatives aimed at reducing packaging.
\end{abstract}

Keywords Packaging $\cdot$ Product display $\cdot$ Naturalness $\cdot$ Origin $\cdot$ Packaging waste $\cdot$ Symbolic barriers

Many products can be displayed with or without a package. Consequently, across varying marketplace contexts, managers display products with and without packaging, seemingly arbitrarily. Supermarkets display packaged and unpackaged versions of products across a number of categories in-store, online, and in weekly circulars. For instance, the produce section of Whole Foods offers bagged carrots and a bin of unpackaged carrots, as well as clamshells of tomatoes alongside stacks of unpackaged tomatoes. Similarly, the bakery department sells cakes, cookies, and donuts packaged as well

The first two authors "Courtney Szocs \& Sara Williamson contributed equally.

\begin{tabular}{l}
\hline Gergana Nenkov served as Area Editor for this article. \\
\hline $\begin{array}{l}\text { Courtney Szocs } \\
\text { cszocs@1su.edu }\end{array}$ \\
Sara Williamson \\
williamsons@oldwestbury.edu \\
Adam Mills \\
ajmills@loyno.edu \\
1 Louisiana State University, Baton Rouge, LA 70808, USA \\
$2 \quad$ SUNY Old Westbury, Old Westbury, NY 11568, USA \\
3 Loyola University New Orleans, New Orleans, LA 70118, USA
\end{tabular}

as unpackaged in display cases. Restaurants also display products with and without packaging. For example, The Coffee Bean \& Tea Leaf at the Atlanta Hartfield Airport sells some fruits and baked goods (e.g., apples, brownies) wrapped and others (e.g., bananas, croissants) unwrapped. Moreover, Starbucks instructs its employees to remove bakery items from their individual packages before placing them unpackaged in a display case, only to re-package them for the customer upon purchase (Perry, 2014). In an online context, we searched the websites of two major retailers (Target, Whole Foods) in two U.S. cities for two products (apples, bath bombs) and recorded whether the image in the search results featured the product packaged, unpackaged, or both. As discussed in Web Appendix A, the findings of our search showed that about $49 \%$ (51\%) of apples were displayed packaged (unpackaged) and $84 \%$ (15\%) of bath bombs were displayed packaged (unpackaged). Thus, both types of products were commonly displayed packaged and unpackaged.

Given that grocery stores, restaurants, and online retailers display products both with and without packaging, and that consumers make inferences about products based on packaging (White et al., 2016; Ye et al., 2020), this research investigates how the presence or absence of packaging on a displayed product influences consumers' product responses. We focus primarily on the effects of packaging in the context 
of food products, but we show that the effects extend to nonfood products that are natural (i.e., originate from humans, plants, or animals; Rozin, 2005, 2006). We address the following question: would consumers respond to a natural product more or less favorably if they saw the product displayed packaged as opposed to unpackaged?

Extant literature fails to provide a definitive answer to this question. Avoiding contamination is a key motivator of product evaluations and choices (Morales \& Fitzsimons, 2007). Consumers avoid products they believe have been in contact with unsavory objects (Morales \& Fitzsimons, 2007) or people (Argo et al., 2006), as well as products with superficial packaging damage (e.g., a torn label; White et al., 2016). In light of recent health concerns (e.g., COVID-19), consumers might be especially sensitive to contamination. Because packaging protects a product from external harm it is possible that consumers will respond to packaged (vs. unpackaged) products more positively.

On the other hand, we propose that in some cases (i.e., when products are natural, and naturalness is important) packaging can lead to less positive product responses. We build our theoretical framework on research that suggests natural products elicit feelings of closeness to nature (Amos et al., 2014), research showing that packaging can function as a physical and symbolic barrier (Cheema \& Soman, 2008; White et al., 2016), and research showing that the physical proximity of a product to its origin is positively associated with naturalness (Román et al., 2017; Staub et al., 2020). We theorize that, in addition to the physical function of separating the product from the external environment, packaging functions as a symbolic barrier that perceptually separates the product from nature making it seem less natural. Naturalness is a positive attribute for foods and some non-food products (Rozin, 2005, 2006; Rozin et al., 2012). Thus, we predict that when consumers encounter a natural product packaged (vs. unpackaged) they will perceive it as less natural and respond to it less favorably.

In testing this prediction, we contribute to theory and practice. From a practical perspective, the findings of this research have implications for sustainability initiatives and product merchandising. Americans discard 14,000 tons of plastic packaging every year (EPA, 2019b). Packaging accounts for $25 \%$ of trash in landfills (EPA, 2019a), and packaging from foods/beverages is a significant contributor to pollution (World Economic Forum, 2016). Due to rising concerns about the harmful effects of pollution, there is interest in reducing packaging (Chapman, 2017). Yet managers would likely not want to reduce packaging at the expense of consumers' product responses. With sustainability issues and consumer responses in mind, we develop a simple decision tree (Fig. 1) to guide managers on how to display natural products.

Theoretically, our findings contribute to three literature streams. First, we extend prior research on the physical, visual, and symbolic effects of packaging. Research in this stream documents primarily positive effects of packaging as a barrier that separates the product from external contaminants (Morales \& Fitzsimons, 2007; Patrick et al., 2017; White et al., 2016), other products (Cheema \& Soman, 2008), and the consumer (Deng \& Srinivasan, 2013) ultimately reducing contamination (Morales \& Fitzsimons, 2007; Patrick et al., 2017; White et al., 2016) and overconsumption (Deng \& Srinivasan, 2013; Cheema \& Soman, 2008). There is also emerging research highlighting positive effects of packaging as a means of connecting the product to its producer (Schroll et al., 2018). We contribute by documenting a symbolic effect of packaging acting as a barrier to products for which naturalness is important.

Second, we contribute to visual perception research. More specifically, we add to the literature on visual positioning, which examines how the location of a product relative to another object influences perception (Sample et al., 2020). Research in this domain shows that a product's position within a display (Romero \& Biswas, 2016) and on a package (Deng \& Kahn, 2009) influences consumers' product choices and evaluations. We extend this work by showing that displaying a product within a package reduces perceptions of product naturalness and ultimately leads to less favorable product responses than displaying the product unpackaged.

Finally, we contribute to the literature on naturalness by identifying packaging as a factor that can reduce perceived naturalness. This finding extends prior research which shows factors other than the products' origin drive perceived naturalness such as beautiful food presentation (Hagen, 2021), earth tone colors on healthy food packages (Marozzo et al., 2020), and matte surfaces on packages of foods that are perceived as somewhat artificial (Marckhgott \& Kamleitner, 2019).

Next, we conceptualize how packaging perceptually separates a product from the plant, animal, or human it originated from, which reduces perceived naturalness, and ultimately leads to less favorable product responses. Then we test our conceptualization with controlled experiments and in the field. Specifically, we establish the negative effects packaging and provide process evidence (Study 1a, 1b), document managerially relevant tactics to offset the effects (Study 2a, 2b, 3), identify a boundary condition (Study 4), and provide evidence of the effects in an ecologically valid context (Study 5). We close by discussing the implications of our work.

\section{Theoretical framework}

\section{Packaging as a symbolic barrier}

Packaging is a physical barrier that serves essential functions such as containing products (e.g., liquids, powders, multipiece items), protecting them from contamination and damage, and preventing direct handling (Krishna et al., 2017). In 


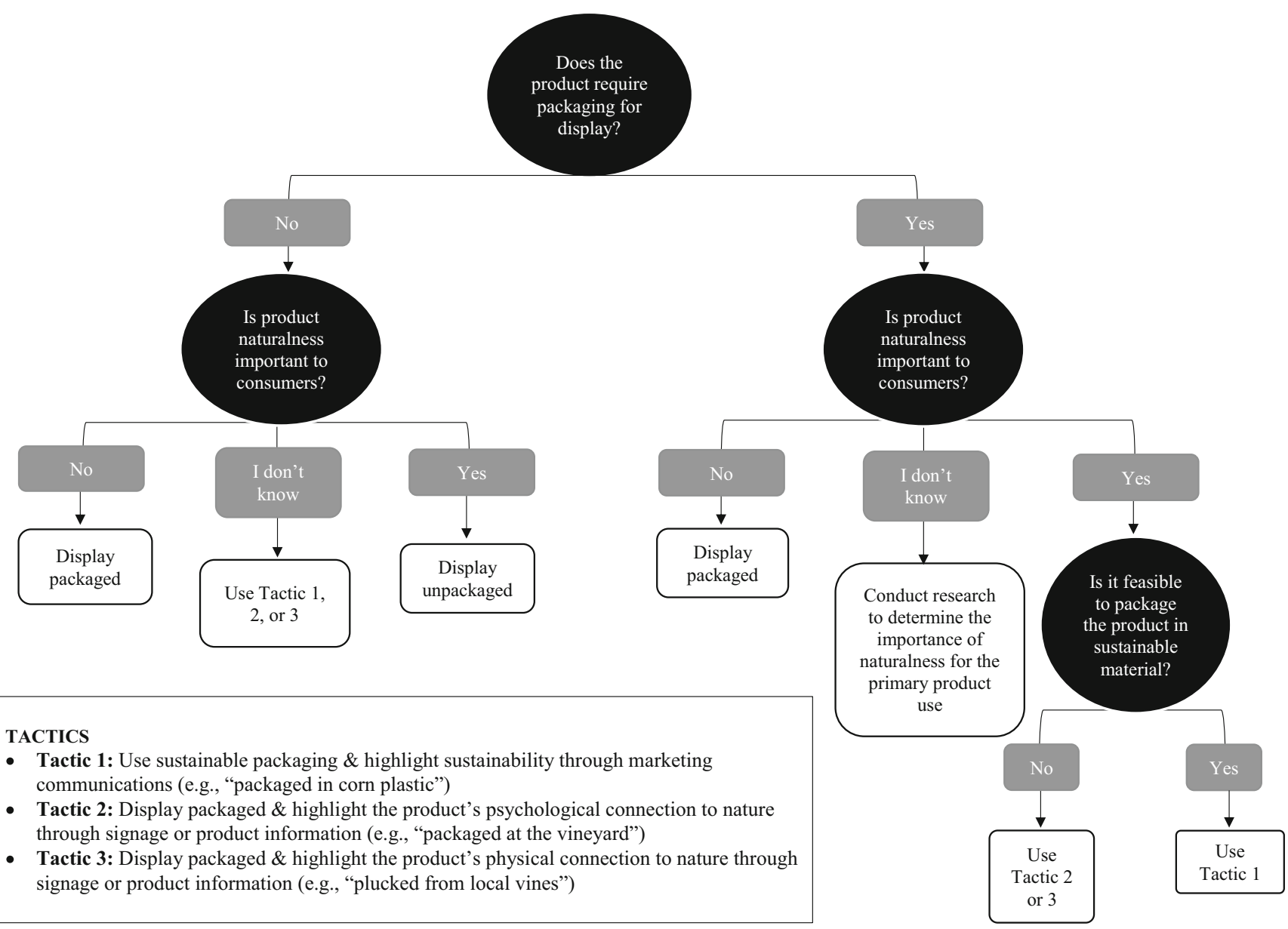

Fig. 1 Packaging decision tree for managers

light of these important physical functions, the prevalence of packaging in the marketplace, and repeated learning that occurs with experiences over time (Van Osselaer \& Alba, 2000), we propose that consumers adopt an intuitive understanding of packaging as a material structure that encapsulates an object and separates it from the external environment. We theorize that this learned association with packaging yields symbolic meaning as well; in particular, that packaging also serves as a symbolic barrier.

To parse out the distinct role of packaging symbolism, we limit the focus of this research to natural products that can be displayed with or without the physical function of a package. Thus, while in some cases packaging is a necessary component of product merchandising for safety or containment reasons, the focus of our research is limited to (1) natural products that don't require protective packaging during display or can be protected by some other means (e.g., a display case, by being out of consumers' reach) or (2) contexts where protection is unnecessary during display (e.g., online, in advertisements).

Prior research suggests that by dividing spaces, visual boundaries and spatial partitions can function as symbolic barriers. For instance, carpet runners and queueing stanchions physically separate an environment, and also function symbolically to separate a task. When consumers are within the perceptual barrier (e.g., on a carpet) they categorize their position as "in the system" and consequently are more likely to prepare for the upcoming task and complete it than when they are "out of the system" or on the other side of the barrier (Zhao et al., 2012). Geographical divisions (e.g., state borders) function as symbolic barriers that perceptually separate two locations into distinct categories (i.e., states) and reduce perceived risk associated with a threat in another category relative to an equidistant threat in the same category (Mishra \& Mishra, 2010). Relatedly, a frame around a logo symbolically protects the brand and increases purchase intentions relative to no frame when consumers are concerned about risk (Fajardo et al., 2016).

There is also evidence that packaging can serve as a physical, visual, and symbolic barrier. For instance, wrappers on chocolates within a box not only act as a physical barrier separating the chocolates, but also act as symbolic barrier to consumption by calling attention to the consumption decision and increasing deliberation (Cheema \& Soman, 2008). 
Similarly, a cardboard divider placed between a product and its exterior package physically separates the product from the outer package, and also functions symbolically by preventing contagious effects of superficial packaging damage from contaminating the product (White et al., 2016). Finally, an opaque package can serve as a visual and symbolic barrier that reduces the perceived contact with a disgusting product relative to a clear package (Morales \& Fitzsimons, 2007). See Table 1 for these and other examples.

Building on the idea that physical barriers, including packaging, function symbolically, and that consumers likely learn over multiple experiences that packaging separates a product from the external environment, we propose that packaging may serve as a symbolic barrier that perceptually separates a natural product from its origin (i.e., nature). We elaborate on this proposition next.

\section{Packaging as perceptual separation from nature}

Consumers are interested in where products originate (Balabanis \& Diamantopoulos, 2004; Zhou et al., 2010) and value products that are physically or psychologically linked to the origin. For instance, individuals prefer products with low serial numbers because the products seem temporally more proximal to the origin than products with high serial numbers (Smith et al., 2016). Additionally, consumers value products manufactured at the original factory more than products manufactured at another company factory because the original factory is more physically proximal to the brand's origin (Newman \& Dhar, 2014).

Consistent with the findings of research on non-natural products (e.g., Newman \& Dhar, 2014; Smith et al., 2016), consumers value physical or psychological connections to the origin with natural products, and especially with food products (Murdoch \& Miele, 2004). Consumer interest in products with natural connections is reflected in the shift away from industrially produced products and towards homemade/grown and human-produced items (Abouab \& Gomez, 2015; Fuchs et al., 2015; Rivaroli et al., 2020), as well as local and organic foods (Schösler et al., 2013). Some scholars (e.g., Hamilton, 2002; Reich et al., 2018) even attribute the popularity of local products and farmers markets to consumer desire for products with close connections to the products' origin since with both farmers markets and locally produced products, the product is more physically proximal to the origin than it would be at larger chain stores or if it was produced non-locally.

Natural products originate from plants, animals, or humans (Rozin, 2005, 2006). Thus, a connection to the product origin is a connection to nature. Prior research conceptualizes naturalness as the perceived closeness of a product to its original state (Ode et al., 2009; Román et al., 2017; Tveit, Ode, \& Fry, 2006), and shows that the word "natural" elicits feelings of closeness to nature (Amos et al., 2014). Building on these ideas, we propose that packaging will reduce perceived product naturalness by symbolically separating the product from nature.

Table 1 Evidence of packaging as a barrier and connector

\begin{tabular}{|c|c|c|c|c|c|}
\hline Study & $\begin{array}{l}\text { Barrier or } \\
\text { connector }\end{array}$ & Type of barrier/connector & Operationalization & $\begin{array}{l}\text { Valence of } \\
\text { effect }\end{array}$ & Effect on consumers \\
\hline Present research & Barrier & Physical and symbolic & Presence of packaging & Negative & $\begin{array}{l}\text { Decreases product evaluations, purchase } \\
\text { likelihood, ad clicks and likes }\end{array}$ \\
\hline Schroll et al. (2018) & Connector & $\begin{array}{l}\text { Symbolic, between consumer } \\
\text { and product }\end{array}$ & Handwritten font & Positive & $\begin{array}{l}\text { Increases emotional attachment and } \\
\text { product evaluations }\end{array}$ \\
\hline Patrick et al. (2017) & Barrier & $\begin{array}{l}\text { Visual, between the product and } \\
\text { external contaminants }\end{array}$ & $\begin{array}{l}\text { Opaque packaging } \\
\text { Closed packaging }\end{array}$ & Positive & $\begin{array}{l}\text { Increases perceptions that the product is } \\
\text { pristine, increases perceived value }\end{array}$ \\
\hline Lin and Shih (2016) & Barrier & Visual and symbolic & Sealed packages & $\begin{array}{r}\text { Positive or } \\
\text { negative }\end{array}$ & $\begin{array}{l}\text { Decreases contagion from adjacent } \\
\text { products }\end{array}$ \\
\hline White et al. (2016) & Barrier & $\begin{array}{l}\text { Physical, between product and } \\
\text { package damage }\end{array}$ & Cardboard divider & Positive & Decreases contamination concerns \\
\hline $\begin{array}{l}\text { Deng and } \\
\quad \text { Srinivasan (2013) }\end{array}$ & Barrier & $\begin{array}{l}\text { Visual, between consumer and } \\
\text { food }\end{array}$ & Opaque packaging & Positive & $\begin{array}{l}\text { Decreases food salience, increases } \\
\text { monitoring }\end{array}$ \\
\hline $\begin{array}{l}\text { Mishra and } \\
\text { Mishra (2010) }\end{array}$ & Both & Visual and symbolic & Package colors & Neutral & Preference for a product grouping \\
\hline $\begin{array}{l}\text { Cheema and } \\
\text { Soman (2008) }\end{array}$ & Barrier & Physical, between product units & Wrappers on chocolates & Positive & $\begin{array}{l}\text { Increases attention and consumption } \\
\text { deliberation }\end{array}$ \\
\hline $\begin{array}{l}\text { Morales and } \\
\text { Fitzsimons } \\
(2007)\end{array}$ & Barrier & $\begin{array}{l}\text { Physical, between a disgusting } \\
\text { and non-disgusting product } \\
\text { Visual, between a disgusting and } \\
\text { non-disgusting product }\end{array}$ & $\begin{array}{l}\text { Space between two } \\
\text { packages Opaque } \\
\text { packaging }\end{array}$ & Positive & Decreases contamination \\
\hline
\end{tabular}


Consistent with our proposition, a closer physical or psychological connection to nature enhances naturalness relative to a more distant connection. In terms of a physical connection, consumers rate wine from their own country as more natural than wine from a geographically distant country (Staub et al., 2020). Local foods, which are by definition proximal to their origin, are thought to be more natural than non-locally produced foods (Guptill \& Wilkins, 2002) and are sought out by consumers interested in natural food (Hasselback \& Roosen, 2015). There is also evidence that closer (vs. more distant) psychological connections to nature enhance naturalness. For instance, consumers rate products as more natural when they can mentally link the products to a natural source such as a plant, animal, or human than to a nonnatural source such as a laboratory or machine (Abouab \& Gomez, 2015; Siegrist \& Sutterlin, 2017). And consumers associate craft foods (i.e., foods resulting from small-scale, human production) with naturalness (Rivaroli et al., 2020).

Next, we discuss how reduced naturalness perceptions for packaged products will influence consumers' product responses.

\section{The negative effects of reduced product naturalness}

Naturalness is a positive attribute for foods and some nonfood products (Rozin, 2005, 2006; Rozin et al., 2012). Halo effects associated with naturalness lead to preferences for natural food (Rozin et al., 2004) and non-food products that persist even when consumers think the natural version is chemically identical to the non-natural version (Rozin et al., 2004). Given the overwhelmingly positive effects of perceived naturalness, we predict that decreased naturalness perceptions for packaged (vs. unpackaged) products will lead to less favorable product responses.

To summarize, we theorize that packaging perceptually separates the product and the plant, animal or human it originated from. Therefore, we predict that encapsulating a natural product in a package will decrease perceptions of product naturalness and consequently lead to less favorable product responses. Formally:

H1 Displaying a natural product encapsulated in a package (vs. unpackaged) will lead to less favorable product responses.

H2 Perceived naturalness will mediate the effect of packaging on product responses.

\section{Overview of empirical work}

Seven studies test the proposed hypotheses. First, Studies 1a and $1 \mathrm{~b}$ document the negative effects of packaging on product responses, provide process evidence, and address alternative explanations. Then, Studies $2 \mathrm{a}, 2 \mathrm{~b}$, and 3 provide additional process evidence and empirically demonstrate managerially relevant tactics to offset the negative effects of packaging. Study 4 shows that the negative effects of packaging attenuate when naturalness is not considered to be an important attribute by consumers. Finally, a field study (Study 5) provides evidence of the negative effects of packaging on consumer responses to a produce subscription box.

\section{Study 1a: Effects of packaging on responses to processed foods}

The purpose of Study 1 was to establish the negative effects of packaging on consumers' product responses with processed food (Study 1a) and non-food stimuli (Study 1b). Additionally, we wanted to test the mediating effects of perceived naturalness $(\mathrm{H} 2)$ and address a number of potential alternative explanations.

\section{Stimuli test}

To ensure that the packaged and unpackaged stimuli did not vary in terms of visual appearance, freshness, or display familiarity we randomly assigned U.S.-based members of Prolific $\left(N=60, \mathrm{M}_{\mathrm{age}}=31.0,28\right.$ females, 1 preferred not to indicate gender) to view a piece of cheesecake displayed on its own or superimposed on the front of a box. Participants were asked to imagine they wanted to buy some cheesecake and came across the cheesecake pictured. To control for product size, the packaged image was created by pasting the slice of cheesecake onto an image of a box. To maintain package realism and also keep product information equivalent across conditions, individuals in the package condition saw the cheesecake displayed on a box with a "Bakery" logo and information stating, "1 slice" and "made with real cream cheese". In the no package condition, individuals saw the same slice of cheesecake and read that it was a slice of Bakery cheesecake that was made with real cream cheese. Participants rated the visual appearance (Lam \& Mukherjee, 2005) and freshness (Zampini \& Spence, 2004) of the cheesecake as well as the display familiarity (Martin \& Stewart, 2001).

Results indicated no difference in the index of visual appearance $\left(\mathrm{F}(1,58)=.09, p=.769, \eta_{\mathrm{p}}{ }^{2}=.001\right)$, the index of display familiarity $\left(\mathrm{F}(1,58)=.08, p=.779, \eta_{\mathrm{p}}{ }^{2}=.001\right)$, or freshness $\left(\mathrm{F}(1,58)=.34, p=.561, \eta_{\mathrm{p}}{ }^{2}=.006\right)$ based on experimental condition. See Web Appendix B for stimuli, C for measures, and $\mathrm{D}$ for results.

\section{Main study}

In this pre-registered study (https://aspredicted.org/blind.php? $\mathrm{x}=\mathrm{gz3n6e})$, U.S.-based members of Prolific $(N=150$, Mage 
$=32.75$, 76 females, 2 prefer not to indicate gender) were randomly assigned to one of two between-subjects conditions (package vs. no package). Individuals viewed one of the two cheesecake images described in the stimuli test and responded to measures of naturalness (Rozin, 2005) and purchase likelihood (Newman \& Dhar, 2014). See Web Appendix C for measures.

\section{Results}

As predicted, ANOVA revealed that participants were less likely to purchase the cheesecake when it was packaged $\left(\right.$ Mno package $_{\text {no package }}=4.55(1.82)$ vs. $\mathrm{M}_{\text {package }}=3.12$ (1.53); F $\left.(1,148)=26.99, p<.001 . \eta_{\mathrm{p}}{ }^{2}=.154\right)$. Participants also rated the cheesecake as less natural when it was packaged (Mno package no package $=3.87(1.65)$ vs. $\mathrm{M}_{\text {package }}=2.68(1.26) ; \mathrm{F}(1,148)=24.23, p<.001, \eta_{\mathrm{p}}{ }^{2}=$ .141). Mediation analysis (Model 4; Hayes, 2018) with 5000 bootstrapped samples indicated a significant negative indirect effect of packaging on purchase likelihood through perceived naturalness, as the $95 \%$ confidence interval did not include zero $($ Effect $=-.95, \mathrm{BSE}=.20,95 \% \mathrm{CI}:[-1.37,-.57])$.

\section{Study 1b: Replication with non-food}

The purpose of this pre-registered study (https://aspredicted. org/blind.php? $\mathrm{x}=\mathrm{er} 93 \mathrm{fx}$ ) was to replicate the negative effects of packaging on product responses with a non-food item. Naturalness is more important for foods than non-foods (Rozin et al., 2004); hence, examining the negative effects of packaging with a non-food item represents a stronger test of our hypothesis. A secondary purpose of Study $1 \mathrm{~b}$ was to examine a number of alternative explanations for the negative effects of packaging.

\section{Stimuli test}

To ensure there were no differences in visual appearance, visibility, perceived size, or certainty based on the presence or absence of packaging we randomly assigned U.S.-based Prolific panelists $(N=100,53$ females, 1 preferred not to indicate gender, $\left.M_{a g e}=31.9\right)$ to view an image of a packaged or unpackaged starfish seashell. To ensure that the starfish was the same size in both conditions, we created the packaged starfish by superimposing the unpackaged starfish on top of an image of a metallic pouch. Participants read the following instructions: "Imagine you are at the beach and want to bring back a starfish shell as a souvenir for someone you know. You come across the shell below at a gift shop." They viewed either the packaged or unpackaged starfish shell and then responded to appearance (Lam \& Mukherjee 2005), size, visibility, and certainty measures in a randomized order before indicating age and gender.

One-way ANOVA revealed no difference in the index of appearance $\left(\mathrm{F}(1,98)=.46, p=.499, \eta_{\mathrm{p}}{ }^{2}=.005\right)$, or certainty when evaluating the shell based on experimental condition $(\mathrm{F}$ $\left.(1,98)=.14, p=.711, \eta_{\mathrm{p}}^{2}=.001\right)$. The packaged starfish was rated as significantly larger $\left(\mathrm{M}_{\text {no package }}=3.84(1.13) \mathrm{vs}\right.$. $\left.\mathrm{M}_{\text {package }}=4.38(1.01) ; \mathrm{F}(1,98)=6.35, p=.013, \eta_{\mathrm{p}}{ }^{2}=.061\right)$ and more visible than the unpackaged starfish $\left(\mathrm{M}_{\text {no }}\right.$ package $=$ 5.88 (1.37) vs. $\mathrm{M}_{\text {package }}=6.4(1.09) ; \mathrm{F}(1,98)=4.44, p=$ $\left..038, \eta_{\mathrm{p}}{ }^{2}=.043\right)$. See Web Appendix B for stimuli, C for measures, and $\mathrm{D}$ for results.

Bigger is often better (Kyung et al., 2017) and products with more space allocated to their display seem more valuable (Sevilla \& Townsend, 2016). Moreover, product visibility positively influences purchasing (Coucke et al., 2019). Thus, demonstrating the proposed effects of packaging with these stimuli provide a strong test of our hypotheses.

\section{Main study}

In the main study, participants read the set of instructions and viewed the packaged or unpackaged starfish shell used in the stimuli test. Then, they responded to measures of naturalness (Rozin, 2005), purchase likelihood (Newman \& Dhar, 2014), and several alternative explanations (i.e., fresh, familiar, manufactured, eco-friendly) in a randomized order before completing measures of age and gender. See Web Appendix $\mathrm{C}$ for measures.

One hundred U.S.-based Prolific panelists (41 females, 3 prefer not to indicate gender; $\mathrm{M}_{\mathrm{age}}=36.21$ ) completed the survey. One participant did not respond to the familiar item and another did not respond to the manufactured item. Due to our pre-registered exclusion criteria (i.e., finishing the survey as indicated by Qualtrics) we retained data from these individuals.

\section{Results}

Consistent with H1, purchase likelihood was lower for the packaged seashell $\left(\mathrm{M}_{\text {no package }}=4.64(1.54)\right.$ vs. $\mathrm{M}_{\text {package }}=$ $\left.3.72(1.84) ; \mathrm{F}(1,98)=7.36, p=.008, \eta_{\mathrm{p}}{ }^{2}=.07\right)$. Additionally, participants who saw the shell packaged rated it as less natural (Mno package no package $=4.90(1.39)$ vs. $\mathrm{M}_{\text {package }}=3.93(1.76) ; \mathrm{F}(1,98)=9.43, p=.003, \eta_{\mathrm{p}}{ }^{2}=$ .088). In support of $\mathrm{H} 2$, mediation analysis (i.e., PROCESS Model 4 with 5000 bootstrapped samples; Hayes, 2018) revealed a negative indirect effect of packaging on purchase likelihood through perceived naturalness (Effect $=-.76$, $\mathrm{BSE}=.27,95 \% \mathrm{CI}:[-1.34,-.26])$. 
Alternative explanations There was no difference in perceived freshness $\left(\mathrm{F}(1,98)=.55, p=.458, \eta_{\mathrm{p}}{ }^{2}=.006\right)$, familiarity $(\mathrm{F}$ $\left.(1,97)=.18, p=.674, \eta_{\mathrm{p}}{ }^{2}=.002\right)$, or perceptions that the shell was manufactured $\left(\mathrm{F}(1,97)=.049, p=.826, \eta_{\mathrm{p}}{ }^{2}=\right.$ $.000)$ based on the presence of packaging. Participants did however rate the packaged product as less eco-friendly $\left(\mathrm{M}_{\text {no_package }}=4.14(1.63)\right.$ vs. $\mathrm{M}_{\text {package }}=3.10(1.61) ; \mathrm{F}(1$, $\left.98)=10.33, p=.002, \eta_{\mathrm{p}}{ }^{2}=.095\right)$. To examine the dominant process driving purchase likelihood, we submitted naturalness along with perceptions of attractiveness, familiarity, ecofriendliness, and manufactured to a parallel mediation analysis (Hayes, 2018; PROCESS model 4, 5000 bootstrapped samples). As illustrated in Table 2, only naturalness and ecofriendliness mediated the effect of packaging on purchase likelihood. While the partially standardized coefficient associated with the indirect effect of naturalness (-.31) was greater than the partially standardized coefficient associated with the indirect effect of eco-friendliness (-.14), a pairwise contrast comparing the two indirect effects revealed no significant difference $($ Effect $=-.29, \mathrm{BSE}=.29,95 \% \mathrm{CI}:[-.94, .20])$. We discuss this more in the next section.

\section{Discussion}

Collectively, the results of Study $1 \mathrm{a}$ and $1 \mathrm{~b}$ show that displaying a product packaged negatively influences consumers' purchase likelihood. This effect holds for multiingredient processed foods and non-food items and is robust to different types of packaging (e.g., a paper box, a metallic zipper pouch). The negative effects of packaging appear to be driven primarily by perceived naturalness. Specifically, the results of the stimuli test for Study 1a suggest the results are not driven by differences in product attractiveness, freshness, or display familiarity. The results of the Study $1 \mathrm{~b}$ stimuli test and main study suggest that the results are also not driven by appearance, certainty, freshness, familiarity, or perceptions that the shell was manufactured. Moreover, as discussed previously, greater perceived size and visibility for the packaged product should positively influence product responses (Coucke et al., 2019; Kyung et al., 2017; Sevilla \& Townsend, 2016). Finally, the presence of packaging did influence how eco-friendly consumers rated the seashell in Study $1 \mathrm{~b}$. This is not surprising given that natural products are often eco-friendly by definition (Girijappa et al., 2019; Handayani et al., 2018) and that naturalness and ecofriendliness were significantly correlated $(r=.453, p<$ .001). As shown in the stimuli test and study in Web Appendix E, the negative effects of packaging replicate when there are no differences in perceived eco-friendliness suggesting differences in eco-friendliness are not the dominant factor driving the negative effects of packaging. Next, Study $2 \mathrm{a}$ and $2 \mathrm{~b}$ provide additional evidence in support of naturalness as the process driving the negative effects of packaging.

\section{Study 2a: Highlighting a product's psychological connection to nature}

The purpose of Study 2 is to provide additional evidence in support of our process mechanism. If our theorizing is correct, and packaging perceptually separates a natural product from nature, then the negative effects of packaging should attenuate when product information highlights the product's psychological connection to nature (Study 2a) or retail signage highlights the product's physical proximity to nature (Study $2 b$ ).

\section{Stimuli test}

We tested the stimuli to ensure there were no differences in visual appearance or display familiarity based on the presence or absence of packaging. Members of Prolific $\left(N=60, \mathrm{M}_{\text {age }}=\right.$ $32.77,29$ females) were randomly assigned to view an image of grapes displayed in a clear package or unpackaged and rate the visual appearance (Lam \& Mukherjee, 2005) of the product as well as display familiarity (Martin \& Stewart, 2001). See Web Appendix C for measures. There were no differences in visual appearance $\left(\mathrm{F}(1,58)=.008, p=.927, \eta_{\mathrm{p}}{ }^{2}=.000\right)$ or display familiarity $\left(\mathrm{F}(1,58)=.12, p=.733, \eta_{\mathrm{p}}{ }^{2}=.002\right)$ based on experimental condition.

\section{Main study}

In this pre-registered study (https://aspredicted.org/blind. php? $\mathrm{x}=\mathrm{dp} 7 \mathrm{gd} 9$ ), we compared purchase likelihood for
Table 2 Results of parallel mediation in Study 1b

\begin{tabular}{llll}
\hline Mediator & Effect & BSE & $\begin{array}{l}\text { 95\% confidence interval } \\
\text { (lower level, upper level) }\end{array}$ \\
\hline Natural & -.54 & .24 & $(-1.10,-.17)$ \\
Fresh & -.02 & .05 & $(-.13, .08)$ \\
Familiar & -.01 & .04 & $(-.10, .05)$ \\
Manufactured & .004 & .05 & $(-.09, .12)$ \\
Eco-friendly & -.25 & .13 & $(-.55,-.03)$ \\
\hline
\end{tabular}


grapes that were packaged with information highlighting a connection to nature to the same package of grapes without information and unpackaged grapes without information. U.S.-based Prolific panelists $(N=240$, Mage $=30.82 ; 132$ females, 3 prefer not to indicate gender) were assigned to one of three between-subjects experimental conditions: no package; packaged no information; packaged with connection information. All participants viewed an image of grapes packaged or unpackaged. Participants in the "packaged with connection information" condition were told, "These grapes were packaged at the vineyard where they were grown." Participants in the other two conditions did not see this statement. Participants responded to naturalness measures (Rozin, 2005) and indicated purchase likelihood (Newman \& Dhar, 2014).

\section{Results}

Purchase likelihood ANOVA revealed significant differences in purchase likelihood based on experimental condition (F (2, $\left.237)=11.79, p<.001, \eta_{\mathrm{p}}{ }^{2}=.091\right)$. Follow up planned contrasts showed that purchase likelihood was lower when participants saw the grapes packaged with no information than when they saw the grapes unpackaged $\left(\mathrm{M}_{\text {no }}\right.$ package $=5.48$ (1.37) vs. $\mathrm{M}_{\text {package_no info }}=4.42(1.74) ; \mathrm{F}(1,237)=20.22$, $p<.001)$ or packaged with connection information $\left(\mathrm{M}_{\text {package_info }}=5.32(1.31) ; \mathrm{F}(1,237)=14.85, p<.001\right)$. There was no difference in purchase likelihood between the no package and package with connection information conditions $(\mathrm{F}(1,237)=.43, p=.510)$.

Perceived naturalness There were significant differences in perceived naturalness based on experimental condition (F (2, $\left.237)=13.08, p<.001, \eta_{\mathrm{p}}{ }^{2}=.099\right)$. As predicted, participants who saw the grapes in a package without information rated them as less natural than participants who saw the grapes unpackaged (Mno package no package $=5.51(1.25)$ vs. $\left.\mathrm{M}_{\text {package_no info }}=4.50(1.48) ; \mathrm{F}(1,237)=22.70, p<.001\right)$ or packaged with connection information $\left(\mathrm{M}_{\text {package_info }}=\right.$ 5.35 (1.27); F $(1,237)=16.08, p<.001)$. There was no difference in perceived naturalness between the no package and package with connection information conditions (F (1, 237) $=.60, p=.441)$.

Process evidence We tested the prediction that packaging influences purchase likelihood through perceptions of naturalness using PROCESS Model 4 with 5000 bootstrapped samples (Hayes, 2018). We used sequential coding for the multi-categorical independent variable to compare the no package condition (coded as 0 ) to the package no information condition (coded as 1) as well as to compare the package no information condition and the package with information condition (coded as 2). Compared to the no package condition, a package without information negatively affected purchase likelihood through reduced naturalness $($ Effect $=-.83, \mathrm{BSE}=.20,95 \% \mathrm{CI}:[-1.23$, $-.45])$. In contrast, compared to a package without information, a package with connection information positively influenced purchase likelihood through increased naturalness $($ Effect $=.69, \mathrm{BSE}=.18,95 \% \mathrm{CI}:[.34,1.06])$.

\section{Study $2 \mathrm{~b}$ : Highlighting a product's physical connection to nature with signage}

The design, procedure, and stimuli were similar to Study 2 a. Specifically, this pre-registered study (https://aspredicted.org/ blind.php? $\mathrm{x}=968 \mathrm{rz} 8$ ) had three between-subjects conditions: no package; package, no information; package with connection information. Individuals were asked to imagine they needed to buy some grapes and came across the grapes pictured. Participants then saw the grapes unpackaged, packaged without information, or packaged next to a sign that read, "Locally grown plucked from local vines." Participants responded to the same naturalness and purchase likelihood measures as in Study 2a. See Web Appendix B for stimuli and $\mathrm{C}$ for measures.

Of the 301 U.S.-based Prolific panelists that started the survey, one individual did not complete any of the measures. Per the pre-registered exclusion criteria, we excluded this individual leaving a final sample of $300\left(\mathrm{M}_{\mathrm{age}}=34.80 ; 141\right.$ females, 2 prefer not to indicate gender).

\section{Results}

Purchase likelihood ANOVA indicated significant differences in purchase likelihood based on experimental condition ( $\mathrm{F}(2$, $\left.297)=8.53, p<.001, \eta_{\mathrm{p}}{ }^{2}=.054\right)$. Follow-up planned contrasts revealed that purchase likelihood was marginally lower when participants saw the grapes packaged without information than when they saw the grapes with no package $\left(\mathrm{M}_{\text {no package }}=5.13(1.38)\right.$ vs. $\mathrm{M}_{\text {package no info }}=4.80(1.50)$; $\mathrm{F}(1,297)=2.79, p=.096)$, or packaged with connection information $\left(\mathrm{M}_{\text {package info }}=5.61(1.34) ; \mathrm{F}(1,297)=16.83\right.$, $p<.001)$. Purchase likelihood was also greater when participants saw the grapes packaged with information than unpackaged $(\mathrm{F}(1,297)=6.01, p=.015)$.

Perceived naturalness As predicted, ANOVA showed significant differences in perceived naturalness based on condition $\left(\mathrm{F}(2,297)=10.68, p<.001, \eta_{\mathrm{p}}{ }^{2}=.067\right)$. Participants who viewed the packaged grapes without information rated them as less natural than participants who viewed the grapes unpackaged $\left(\mathrm{M}_{\text {no package }}=5.28(1.14)\right.$ vs. $\mathrm{M}_{\text {package_no info }}=$ 
$4.93(1.32)$; F $(1,297)=3.84, p=.051)$ or packaged with information $\left(\mathrm{M}_{\text {package_info }}=5.74(1.27) ; \mathrm{F}(1,297)=21.17\right.$, $p<.001)$. Participants who saw the packaged grapes with information highlighting their connection to nature rated them as more natural than participants who viewed the unpackaged grapes $(\mathrm{F}(1,297)=7.08, p=.008)$.

Mediation We used PROCESS model 4 with 5000 bootstrapped samples (Hayes, 2018) to examine the indirect effects of packaging on purchase likelihood through perceived naturalness. We used sequential coding for the multicategorical independent variable to compare the no package condition (coded as 0 ) to the package, no information condition (coded as 1) and the package, no information condition to the package with information condition (coded as 2). The results showed a marginally significant negative indirect effect of packaging relative to no packaging on purchase likelihood through naturalness $($ Effect $=-.28, \mathrm{BSE}=.14,90 \% \mathrm{CI}$ : $[-.52,-.05])$ and a positive indirect effect of packaging with information relative to without information on purchase likelihood through naturalness $($ Effect $=.66, \mathrm{BSE}=.15,90 \% \mathrm{CI}$ : $[.41, .91])$.

\section{Discussion}

Collectively, the results of Study $2 \mathrm{a}$ and Study $2 \mathrm{~b}$ provide additional evidence in support of our theorizing that packaging perceptually separates the product from nature reducing perceived naturalness and ultimately purchase likelihood. The results of Study 2 also suggest two tactics managers can use to offset the negative effects of packaging. Specifically, managers can highlight the product's psychological or physical connection to nature with product information or retail signage. Interestingly, the results of Study $2 \mathrm{~b}$ show that highlighting the physical connection to naturale led to greater naturalness and product evaluations than displaying the product unpackaged. Next, Study 3 identifies another tactic managers can use to offset the negative effects of packaging.

\section{Study 3: Using natural packaging material to offset negative effects of packaging}

The purpose of Study 3 was to provide additional evidence for our proposed process mechanism as well as to identify another tactic for managers to offset the negative effects of packaging. Study 3 examines whether informing consumers about the use of natural packaging materials will reduce perceptual separation of the product from nature.

We propose that the negative effects of packaging are driven by packaging acting as a symbolic barrier rather than the physical barrier. Consistent with this, whether packaging functions as a barrier protecting the product from contaminating effects of disgusting products depends on perceived contact with the disgusting product, not actual contact (Morales \& Fitzsimons, 2007). Hence, the contaminating effects of disgusting products occur when packaging is transparent but attenuate when packaging is opaque (i.e., a visual barrier) (Morales \& Fitzsimons, 2007). Additionally, the contaminating effects of package damage are contingent on perceptual separation between the product and the package rather than physical separation. Thus, the negative effects of package damage occur when the product is physically separated by an enclosed package but attenuate when a buffer enhances perceptual separation (White et al., 2016). In the context of the present research, we are predicting that negative effects of packaging stem from the perception that the package separates the product from nature, reducing naturalness. Thus, if consumers learn that a product is packaged in natural material they should no longer perceive the package as separating the product from nature. Specifically,

H3 Displaying a natural product encapsulated in a package (vs. unpackaged) will lead to less favorable product responses. However, the negative effects of packaging will attenuate when consumers believe packaging material is natural.

In line with our prediction, there is some evidence that sustainable packaging can increase perceptions of product naturalness. For instance, Magnier et al. (2016) manipulate package sustainability by varying packaging materials and show that consumers rate products in packaging that appears sustainable as more natural than products in packaging that has a conventional appearance.

\section{Stimuli test}

To ensure there were no systematic differences in freshness, product appearance, or display familiarity based on the presence or absence of packaging, we randomly assigned 60 Prolific panelists (32 females, 28 males; $M_{\text {age }}=31.35$ ) to view a loaf of banana bread either unpackaged or in a clear plastic package. While viewing one of the two images, participants responded to measures of freshness (Zampini \& Spence, 2004), product appearance (Lam \& Mukherjee, 2005), and display familiarity (Martin \& Stewart, 2001) in a randomized order. There were no differences in perceived freshness based on packaging $(\mathrm{F}(1,58)=.23, p=.632$, $\left.\eta_{\mathrm{p}}{ }^{2}=.004\right)$. The packaged banana bread was rated as less attractive $\left(\mathrm{M}_{\text {no package }}=4.34(1.47)\right.$ vs. $\mathrm{M}_{\text {package }}=3.28$ $\left.(1.31) ; \mathrm{F}(1,58)=8.69, p=.005, \eta_{\mathrm{p}}{ }^{2}=.130\right)$, and as having a less familiar display $\left(\mathrm{M}_{\text {no package }}=3.81(1.74) \mathrm{vs}\right.$. $\mathrm{M}_{\text {package }}=2.88(1.14) ; \mathrm{F}(1,58)=5.90, p=.018, \eta_{\mathrm{p}}{ }^{2}=$ $.092)$. 


\section{Design, participants, procedure}

In this pre-registered study (https://aspredicted.org/blind.php? $\mathrm{x}=\mathrm{q} 2 \mathrm{dp6c})$, U.S.-based members of Prolific $(N=200 ; 94$ females, 102 males, 4 preferred not to indicate gender; $\mathrm{M}_{\text {age }}=32.80$ ) were randomly assigned to one of three conditions (package, no information vs. package, natural information vs. no package). Individuals were asked to imagine they were at the grocery store and needed to purchase a loaf of banana bread. They were told to imagine they came across the product pictured. Participants saw an image of banana bread in a clear package or without a package (no package). In the package with information condition (package_info), participants were informed that the product was packaged in "a biodegradable plastic made from corn". This information was absent in the package, no information condition (package_no info). Participants responded to product evaluation (Fuchs et al., 2015) and naturalness measures (Rozin, 2005). Then, participants advanced to the next page and completed manipulation check measures related to the naturalness of conventional and corn plastic. See Web Appendix B for stimuli and C for measures.

\section{Results}

Manipulation check Consistent with the intended manipulation, a paired samples t-test showed individuals perceived corn plastic as more natural than conventional plastic $\left(\mathrm{M}_{\text {corn }}=3.96(1.52)\right.$ vs. $\mathrm{M}_{\text {conventional }}=1.99$ (1.43); $\mathrm{t}$ (199) $=-15.09, p<.001)$.

Product evaluations ANOVA revealed a significant effect of packaging on product evaluations $(\mathrm{F}(2,197)=7.22, p=$ $\left..001, \eta_{\mathrm{p}}{ }^{2}=.068\right)$. Consistent with $\mathrm{H} 3$, evaluations were less favorable when participants saw the banana bread packaged without information compared to unpackaged $\left(\mathrm{M}_{\text {no package }}=\right.$ 3.10 (1.06) vs. $\mathrm{M}_{\text {package no info }}=2.56(1.19) ; \mathrm{F}(1,197)=$ $7.26, p=.008)$ or packaged with information $\left(\mathrm{M}_{\text {package info }}=\right.$ 3.29 (1.23); F $(1,197)=13.42, p<.001)$. There was no difference in product evaluations between the package with information and no package conditions $(\mathrm{F}(1,197)=.91, p=$ .340) suggesting that natural packaging material offset the negative effects of packaging.

Naturalness ANOVA revealed significant differences in perceived naturalness based on experimental condition (F (2, 197) $\left.=7.23, p=.001, \eta_{\mathrm{p}}{ }^{2}=.068\right)$. Participants who saw the banana bread in a package without information rated it as less natural than participants who saw the banana bread unpackaged $\left(\mathrm{M}_{\text {no package }}=3.91(1.71)\right.$ vs. $\mathrm{M}_{\text {package_no info }}=$ $3.01(1.56) ; \mathrm{F}(1,197)=10.36, p=.002)$ or packaged with information $\left(\mathrm{M}_{\text {package_info }}=3.95(1.61) ; \mathrm{F}(1,197)=11.29\right.$, $p=.001)$. There was no difference in perceived naturalness between participants who saw the banana bread in a package with information and participants who saw it unpackaged (F $(1,197)=.02, p=.898)$.

Mediation We tested the indirect effect of packaging on product evaluations through perceived naturalness using PROCESS Model 4 with 5000 bootstrapped samples (Hayes, 2018) with sequential coding for the multicategorical predictor variable. Compared to the unpackaged condition (coded as 0 ), the package no information condition (coded as 1) had a negative indirect effect on product evaluations through perceived naturalness $($ Effect $=-.36$; BSE $=$ $.12,95 \%$ CI: [-.61, -.13$])$. Compared to the package without information, a package with natural material information (coded at 2) had a positive indirect effect on product evaluations through naturalness $($ Effect $=.37, \mathrm{BSE}=.12,95 \%$ CI: $[.15$, $.63])$.

\section{Discussion}

Study 3 shows that the negative effects of packaging on product responses attenuate when consumers learn the package is made from natural material. This result supports our theorizing and suggests that managers can offset the negative effects of packaging by making consumers aware of the use of natural packaging materials. Next, Study 4 identifies a boundary condition to the negative effects of packaging by showing that the effects attenuate when naturalness is not a valued product attribute.

\section{Study 4: Importance of product naturalness}

Our theoretical framework rests on the assumption that naturalness positively affects product evaluations. Consistent with our theorizing, naturalness is generally a positive attribute (Rozin, 2005, 2006; Rozin et al., 2012). However, it is not equally important for all products (Rozin et al., 2004). For example, while most individuals prefer natural foods, naturalness is less valued for medicines and may even undermine medicine's perceived effectiveness (Rozin et al., 2004). In fact, Rozin et al. (2004) showed that the majority of participants in study one did not prefer natural medicines or hybrid foods/medicines (e.g., vitamins). We predict that the negative effects of packaging on product responses will hold when product naturalness is important but will attenuate when naturalness is not important.

$\mathrm{H} 4$ When product naturalness is not important, the negative effect of packaging on product responses will attenuate. 


\section{Stimuli test}

We conducted a pretest of our manipulation of the "importance of naturalness." Participants were instructed, "Imagine you are at the beach and want to bring back a starfish shell as a souvenir for someone you know." Participants in the naturalness important condition were then told: "It's important that the starfish shell you bring back is natural." Participants in the naturalness not important condition were told: "It doesn't matter if the starfish shell you bring back is natural or not." On the next page participants were asked, "How important is it that the shell you bring back is natural?" ( 1 = not at all important, 7 = very important).

We requested 100 U.S.-based Prolific panelists; however, 101 panelists completed the survey $\left(\mathrm{M}_{\mathrm{age}}=33.18,62 \mathrm{fe}-\right.$ males, 1 preferred not to indicate gender). Consistent with the intended manipulation, participants in the naturalnessimportant condition rated naturalness as more important than participants in the naturalness-not important condition $\left(\mathrm{M}_{\text {important }}=6.44(.86)\right.$ vs. $\mathrm{M}_{\text {not }}=3.16(2.20) ; \mathrm{F}(1,99)=$ $\left.96.54, p<.01, \eta_{\mathrm{p}}^{2}=.494\right)$.

\section{Design, procedure, participants}

Study 4 had a 2 (packaging: package vs. no package) $\times 2$ (importance of naturalness: important vs. not important) between-subjects design. Members of Prolific $(N=301$, Mage $=32.87,160$ females, 6 prefer not to indicate gender) read one of the two pretested prompts for naturalness importance (i.e., that they wanted to buy a starfish shell and naturalness was important or didn't matter). Then, participants were shown the packaged or unpackaged starfish shell used in Study $1 \mathrm{~b}$ and told they came across the shell at a gift shop. They responded to a three-item naturalness measure (Rozin, 2005), a four-item product evaluation measure (Fuchs et al., 2015), and then indicated age and gender.

\section{Results}

Evaluations A 2 (packaging) $\times 2$ (importance of naturalness) ANOVA revealed only a significant main effect of packaging which showed that participants evaluated the starfish more favorably when it was displayed without a package $\left(\mathrm{M}_{\text {no package }}=3.56(.97)\right.$ vs. $\mathrm{M}_{\text {package }}=3.23(1.22) ; \mathrm{F}(1$, $\left.297)=6.79, p=.01, \eta_{\mathrm{p}}{ }^{2}=.022\right)$. The main effect of importance of naturalness $\left(\mathrm{F}(1,297)=.24, p=.626, \eta_{\mathrm{p}}{ }^{2}=.001\right)$ and the interaction were not significant $(\mathrm{F}(1,297)=.00, p=$ $\left..994, \eta_{\mathrm{p}}^{2}=.000\right)$.

Perceived naturalness A 2 (packaging) $\times 2$ (importance of naturalness) ANOVA revealed only a significant main effect of packaging, where naturalness perception was lower among those who saw the product in a package $\left(\mathrm{M}_{\text {no package }}=5.06\right.$ $(1.33)$ vs. $\mathrm{M}_{\text {package }}=4.38(1.70) ; \mathrm{F}(1,297)=14.77, p<$ $\left..001, \eta_{\mathrm{p}}{ }^{2}=.047\right)$. The main effect of importance of naturalness $\left(\mathrm{F}(1,297)=.081, p=.776, \eta_{\mathrm{p}}{ }^{2}=.000\right)$ and the interaction were not significant $\left(\mathrm{F}(1,297)=.065, p=.799, \eta_{\mathrm{p}}{ }^{2}=\right.$ $.000)$.

Process evidence We predicted that the effects of packaging on product evaluations would hold when participants were told naturalness was important but would attenuate when participants were told naturalness didn't matter. We theorized that this would occur because the reduced naturalness perceptions that result from packaging should reduce product evaluations when naturalness is an important product attribute but should not reduce evaluations when product naturalness was not important. We tested these predictions with PROCESS Model 15 with 5000 bootstrapped samples (Hayes, 2018). Consistent with our prediction, the index of moderated mediation was significant (Index $=-.09, \mathrm{BSE}=.05,95 \% \mathrm{CI}$ : $[-.21,-.01])$ suggesting that the indirect effect of packaging on product evaluations through perceived naturalness varied based on whether naturalness was important. Also as predicted, there was a negative indirect effect of packaging on product evaluations through perceived naturalness when naturalness was important $($ Effect $=-.35, \mathrm{BSE}=.10,95 \% \mathrm{CI}$ : $[-.54,-.17])$. Unexpectedly, there was also a significant indirect effect of packaging on product evaluations through perceived naturalness when naturalness was not important $($ Effect $=-.26$, BSE $=.08,95 \%$ CI: $[-.42,-.12]$; See Table 3$)$. The latter result suggests that packaging negatively affected product evaluations by reducing perceived product naturalness even when participants were told that naturalness did not matter.

\section{Discussion}

The results of Study 4 show that reduced naturalness that results from displaying a product in packaging is more detrimental to product evaluations when naturalness is important than when it is not. Interestingly, packaging still negatively impacted product evaluations when participants were told that it did not matter if the shell was natural. We replicated Study 4 with a different non-food item (i.e., a sponge) and a different manipulation of naturalness importance (i.e., based on product use). As discussed in Web Appendix E, the results showed that packaging negatively impacted product responses when naturalness was important, but unexpectedly positively impacted product responses when naturalness was not important. We discuss this finding more in the General Discussion section. Collectively, the results of Study 4 and its replication suggest managers should carefully consider the importance 
Table 3 Results of moderated mediation in Study 4

\begin{tabular}{|c|c|c|c|c|c|c|c|c|}
\hline & \multicolumn{4}{|c|}{ Perceived naturalness (M) } & \multicolumn{4}{|c|}{ Product evaluations (Y) } \\
\hline & Coefficient & $\mathrm{SE}$ & $\mathrm{t}$ & $p$ & Coefficient & SE & $\mathrm{t}$ & $p$ \\
\hline Packaging (X) & -.68 & .18 & -3.85 & .0001 & -.09 & .14 & -.61 & .54 \\
\hline Perceived naturalness (M) & & & & & .39 & .05 & 8.51 & $<.001$ \\
\hline Importance of naturalness $(\mathrm{V})$ & & & & & -.75 & .36 & -2.10 & .04 \\
\hline $\begin{array}{l}\text { Packaging } \mathrm{x} \text { importance of } \\
\text { naturalness }\end{array}$ & & & & & .13 & .20 & .65 & .52 \\
\hline $\begin{array}{l}\text { Perceived naturalness } \mathrm{x} \\
\text { importance of naturalness }\end{array}$ & & & & & .14 & .07 & 2.11 & .04 \\
\hline Constant & 5.06 & .13 & 40.37 & $<.001$ & 1.64 & .25 & 6.56 & $<.001$ \\
\hline
\end{tabular}

of naturalness when deciding whether to display products packaged or unpackaged.

\section{Study 5: Field experiment using Instagram ads}

The purpose of Study 5 was to establish the substantive importance of our investigation in an ecologically valid context. Study 5 examined how displaying the same products packaged (vs. unpackaged) in online advertisements influenced advertising responses. We predicted that an ad featuring unpackaged produce would generate a larger proportion of clicks and likes relative to ad reach (i.e., number of accounts exposed to the ad) than an ad featuring packaged produce).

We created a business page on Instagram for a company called "Sunshine Box" and populated the profile with assorted images of produce. The profile information said, "Coming soon." Then, we created two advertisements for our study. The ads featured an image of the same assortment of fruits and vegetables either packaged or unpackaged with a tagline that read, "Produce delivered to your door 1, 2, 3 or 4 times a month." See Web Appendix B for stimuli. The ads were promoted on Instagram to appear in user newsfeeds. We posted the unpackaged ad on two weekdays one week, and the packaged ad on the same two weekdays the next week, with the same reach and budget specified for each day.

\section{Results}

The reach for the ads featuring the unpackaged (packaged) assortment of products was 9019 (13,640). As predicted, the ad featuring the unpackaged assortment of products generated a larger proportion of clicks relative to its reach $(197 / 9019=$ $2.18 \%)$ than the ad featuring the packaged products (195/ $\left.13,640=1.43 \% ; \chi^{2}=18.19, p<.001\right)$. Additionally, the ad featuring the unpackaged assortment of products generated a larger proportion of likes relative to its reach $(89 / 9019=$ $.99 \%)$ than the ad featuring the packaged products $(33 / 13,640$ $\left.=.24 \% \chi^{2}=56.25, p<.001\right)$.

\section{Discussion and post-test}

The results provide evidence of the negative effects of packaging on consumers' product responses in an ecologically valid context. However, there are some limitations to this study. First, due to the nature of the study, we were not able to randomly allocate participants to the experimental conditions. Second, while care was taken to display the products similarly in both conditions, there were some subtle differences between images. Specifically, a post-test among U.S.based Prolific panelists who use Instagram $(N=100,59$ women, 2 prefer not to indicate gender, $\left.M_{\text {age }}=29.59\right)$ showed that while the stimuli did not differ in terms familiarity $(\mathrm{F}(1,98)=$ $\left.1.56, p=.215, \eta_{\mathrm{p}}{ }^{2}=.016\right)$ or perceived size $(\mathrm{F}(1,98)=2.74$, $\left.p=.101, \eta_{\mathrm{p}}{ }^{2}=.027\right)$, participants rated the packaged produce as less fresh $\left(\mathrm{F}(1,98)=10.56, p=.002, \eta_{\mathrm{p}}{ }^{2}=.097\right)$, and the appearance as less favorable $(\mathrm{F}(1,98)=10.97, p=.001$, $\left.\eta_{\mathrm{p}}{ }^{2}=.101\right)$. While these results suggest that the negative effects of packaging on ad clicks and likes could have been driven by decreased perceived freshness or a less favorable appearance of the produce in the packaged ad evidence from the controlled studies reported previously suggest that freshness and appearance are not the dominant processes driving the negative effects of packaging.

\section{General discussion}

The results of seven studies show that displaying natural products encapsulated in packaging (vs. unpackaged) leads to a lower proportion of ad clicks and likes (Study 5), less favorable product evaluations (Study 3,4), and decreased purchase likelihood (Study 1a, 1b, 2a, 2b). The negative effects of packaging are robust to whole foods (Study 2a, $2 \mathrm{~b}, 5$ ), processed foods (Study 1a, 3), and non-food items (Study 1b,4) displayed alone (Study 1a-4) or as a group (Study 5). The effects also emerge in contexts where the product would be packaged for purchase (e.g., a gift shop; Study 1 b, 3, 4), or shipment (e.g., online; Study 5) as well as when the context is not specified (Study 1a, 2a, 2b). 
Decreased naturalness perceptions are more dominant in driving the negative effects of packaging than freshness, display familiarity, or perceptions that the product is manufactured. It is also unlikely that the observed effects were driven by differences in perceived size, product appearance, or eco-friendliness since, as illustrated in Web Appendix D, there were no consistent differences in perceptions of the packaged and unpackaged products across our seven studies. Consistent with our theorization, the negative effects of packaging attenuate when product information highlights the product's psychological (Study 2a) or physical connection to nature (Study $2 b$ ), consumers learn packaging is made from natural material (Study 3), and naturalness is not important (Study 4). These findings have theoretical and practical implications.

\section{Theoretical implications}

Our findings extend prior work on packaging, particularly related to the effects of packaging as a barrier. Research in this stream identifies many positive effects that result from packaging functioning as a barrier that protects the product from external contaminants (Morales \& Fitzsimons, 2007; Patrick et al., 2017; White et al., 2016) and protects the consumer from the allure of the product (Cheema \& Soman, 2008; Deng \& Srinivasan, 2013). We add to this stream by identifying instances when packaging leads to negative effects. Specifically, we show that packaging negatively affects product responses when products are natural, naturalness is important, and the product's connection to nature is not enhanced through some other means (e.g., product information, signage).

We also add to the sensory marketing literature on visual perception. Our work specifically adds to visual perception research related to location and positioning which encompasses research on the positioning of one product relative to another (Sample et al., 2020). Research in this domain has examined various aspects of product positioning (e.g., in a display, on a package; Deng \& Kahn, 2009; Romero \& Biswas, 2016). We contribute by showing that displaying a product within a package leads to reduced naturalness and less favorable product responses relative to displaying the product without a package.

Finally, we extend prior work on naturalness by identifying enclosed packaging as a driver of perceived naturalness for products that originate from humans, plants or animals (i.e., natural products). While prior work identifies several factors that can enhance or reduce naturalness (Hagen, 2021; Marckhgott \& Kamleitner, 2019; Marozzo et al., 2020), we are not aware of any work showing that displaying a natural product encapsulated in a package reduces perceived naturalness.

\section{Practical implications}

Recently there has been interest in reducing unnecessary packaging (Chapman, 2017). Retailers such as Walmart, Target, and Trader Joes have pledged to reduce packaging (Chhabra, 2019; Chua, 2019). Other retailers emphasize eradication of packaging as a point of differentiation. For instance, Berlinbased supermarket The Original Unverpackt sells products without packages and requires consumers to either bring their own containers or purchase reusable containers for bulk merchandise (Borromeo, 2014). Zero Market in Colorado offers many products without packages and when packaging is necessary Zero Market uses low impact or plastic free options (Chapman, 2017; Zero Market, 2019). To assist retailers with sustainability efforts, we provide a decision tree to identify when to reduce unnecessary packaging.

Beyond the environmental benefits of reducing packaging, the findings of our research have implications for product merchandising. While Target, Walmart, and Trader Joes are focused on reducing packaging, other retailers have introduced packaged versions of previously unpackaged products. For instance, Whole Foods introduced packages of peeled oranges (Danovich, 2016) and Sobey's, a Canadian grocery chain, introduced packaged avocado halves (Bulow, 2016). Consumer responses to the new packaged versions of products have been mixed. Some consumers have praised retailers' sensitivity to varying consumer needs while others have spoken out against the retailers (Danovich, 2016). These conflicting retail strategies and mixed consumer responses suggest managers could benefit from a clearer understanding of the nuanced effects that packaging has on consumers' product responses. We offer a decision tree to guide managers on when to merchandise products with and without packages.

As shown in Fig. 1, when managers have the option of displaying products with or without packages and product naturalness is important, they should display products unpackaged. Displaying products unpackaged would reduce costs associated with packaging and bolster product responses representing a double win for managers. When managers are unsure about the importance of product naturalness, or it is necessary to display products in packages, they can minimize negative effects of packaging on product responses by using one of three tactics. First, if managers have control over packaging, they can utilize natural packaging materials and highlight package naturalness. Alternatively, managers can display the product packaged and offset the negative effects of packaging by providing information highlighting the products' psychological connection to nature (tactic two) or highlighting the products' physical connection to nature (tactic three). Since retailers often have discretion over the information they convey through signage and product displays, tactics two and three represent low cost, easy to implement ways to offset negative effects of packaging. 


\section{Limitations and future research}

The focus of the present research was limited to natural products that do not require packaging for display purposes (e.g., non-liquids) as well as products that could be protected from damage and contamination by some other means than a package (e.g., by being displayed on a website). There are likely cases where health and safety concerns would be relevant and potentially more important than product naturalness. For instance, when buying a piece of fruit for immediate consumption, health and safety concerns might outweigh the importance of naturalness. As the results of Study 4 and the replication in Web Appendix E suggest, the negative effects of packaging attenuate (and can even reverse) when naturalness is not important. Future research should investigate contexts where other attributes such as health and safety concerns would trump the importance of naturalness in driving product responses.

Packaging offers benefits beyond physical containment and protection (Krishna et al., 2017), including communicating product information (Ye et al., 2020). We held product information constant across conditions to isolate the effects of packaging. There could, however, be scenarios when packaged products might provide more information than unpackaged products. Future research should examine whether the negative effects of packaging hold in these situations.

We aimed to keep aesthetics as similar as possible across experimental conditions. Accordingly, we used transparent packaging (Study 2, 3, 5), or superimposed the image of the product on the image of the package (Study 1a, 1b, 4). There could be aesthetic package features such as the earth tone colors (Marozzo et al., 2020) or matte textures (Marckhgott \& Kamleitner, 2019) which might offset the negative effects of packaging. Future research should examine these features.

Certain segments of consumers might be especially sensitive to the effects of packaging on product evaluations. For instance, some consumers are more environmentally conscious than others and this environmental consciousness influences marketplace behaviors (Haws et al., 2014). Consumers with strong pro-environmental values might have especially strong negative reactions to what they perceive as unnecessary or excess packaging. By the same token, other consumers might be sensitive to germs or contamination and therefore prefer packaged products. Future research should examine these and other individual factors which might moderate the effects of packaging on product responses.

The results of Study $2 \mathrm{a}$ and $2 \mathrm{~b}$ suggest that when the product's physical or psychological connection to nature is salient, the negative effects of packaging attenuate. Would the effects hold when both the product and the consumer were from the local (surrounding) area? What might happen when neither the consumer nor the product were from the local area? On the one hand, connection to nature might already be enhanced when shopping local items in a local store, and consequently, packaging might not negatively affect product responses (as we saw when signage emphasized a local connection). On the other hand, when consumers are shopping far from home, they might prefer packaged products for protection during the commute home. Future research should examine how the consumers' and products' relationship to the point of purchase influence the observed effects of packaging on product responses.

In sum, the present work contributes a more nuanced understanding of when and why packaging negatively impacts product responses. Our findings provide valuable insights and opportunities for future research that extend to merchandising strategies and sustainability initiatives.

Supplementary Information The online version contains supplementary material available at https://doi.org/10.1007/s11747-021-00800-3.

\section{References}

Abouab, N., \& Gomez, P. (2015). Human contact imagined during the production process increases food naturalness perceptions. Appetite, 91, 273-277.

Amos, C., Pentina, I., Hawkins, T. G., \& Davis, N. (2014). 'Natural' labeling and consumers' sentimental pastoral notion. Journal of Product \& Brand Management, 23, 268-281.

Argo, J., Dahl, D. W., \& Morales, A. C. (2006). Consumer contamination: How consumers react to products touched by others. Journal of Marketing, 70, 81-94.

Balabanis, G., \& Diamantopoulos, A. (2004). Domestic country bias, country-of-origin effects and consumer ethnocentrism: A multidimensional unfolding approach. Journal of the Academy of Marketing Science, 32, 80-95.

Borromeo, L. (2014). Berlin duo launch a supermarket with no packaging. Retrieved January 6, 2020 from https://www.theguardian.com/ sustainable-business/2014/sep/16/berlin-duo- supermarket-nopackaging-food-waste.

Bulow, A. (2016). This peeled avocado is causing viral internet outrage. Retrieved May 11, 2020 from https://www.today.com/food/peeledavocado-causing-viral-internet-outrage-t81036

Chapman, I. (2017). Zero waste isn't just for hippies anymore. Retrieved January 8, 2020 from https://www.cnn.com/2017/05/01/health/ zero-waste-package-free-trnd/index.html

Cheema, A., \& Soman, D. (2008). The effect of partitions on controlling consumption. Journal of Marketing Research, 45, 665-675.

Chhabra, E. (2019). How trader Joe's is cutting down on plastic. Retrieved May 11, 2020 from https://www.forbes.com/sites/ eshachhabra/2019/07/30/how-trader-joes-is-cutting-down-onplastic/\#31c9057835fc

Chua, J. M. (2019). Plastic waste is everywhere in grocery stores. Can they cut it down? Retrieved January 8, 2020 from https://www.vox. com/2019/10/9/20885735/grocery-store-plastic-waste- producealdi-walmart.

Coucke, N., Vermein, I., Slabbinck, H., \& Kerckhove, V. (2019). Show me more! The influence of visibility on sustainable food choices. Foods, 8, 186.

Danovich, T. (2016). Pre-peeled oranges: What some call 'lazy' others call a 'lifesaver'. Retrieved May 11, 2020 from https://www.npr.org/ sections/thesalt/2016/03/07/469521879/pre-peeled-oranges-whatsome-call-lazy-others-call-a-lifesaver 
Deng, X., \& Kahn, B. E. (2009). Is your product on the right side? The "location effect" on perceived product heaviness and package evaluation. Journal of Marketing Research, 46, 725-738.

Deng, X., \& Srinivasan, R. (2013). When do transparent packages increase (or decrease) food consumption? Journal of Marketing, 77, 104-117.

EPA (2019a). Containers and packaging: Product-specific data. Retrieved November 20, 2019 from https:/www.epa.gov/facts-and-figuresabout-materials-waste-and-recycling/containers-and-packagingproduct-specific-data

EPA (2019b). Reducing wasted food and packaging: A guide for food services and restaurants. Retrieved May 11, 2020 from https://www. epa.gov/sustainablemanagement-food/resources-assessing- wastedfood.

Fajardo, T. M., Zhang, J., \& Tsiros, M. (2016). The contingent nature of the symbolic associations of visual design elements: The case of brand logo frames. Journal of Consumer Research, 43, 549-566.

Fuchs, C., Schreier, M., \& Van Osselaer, S. M. J. (2015). The handmade effect: What's love got to do with it? Journal of Marketing, 79, 98 110

Girijappa, Y. G. T., Rangappa, S. M., Parameswaranpillai, J., \& Siengchin, S. (2019). Natural fibers as sustainable resource for development of eco-friendly composites: A comprehensive review. Frontiers in Materials, 6, 226.

Guptill, A., \& Wilkins, J. L. (2002). Buying into the food system: Trends in food retailing in the us and implications for local foods. Agriculture and Human Values, 19, 39-51.

Hagen, L. (2021). Pretty healthy food: How and when aesthetics enhance perceived healthiness. Journal of Marketing, 85, 129-145.

Hamilton, N. D. (2002). Putting a face on our food: How state and local food policies can promote the new agriculture. Drake Journal of Agricultural Law, 7, 407-454.

Handayani, W., Kristijanto, A. I., \& Hunga, A. I. R. (2018). Are natural dyes eco-friendly? A case study on usage and wastewater characteristics of batik production by natural dyes application. Sustainable Water Resources Management, 4, 1011-1021.

Hasselback, J. L., \& Roosen, J. (2015). Motivations behind preferences for local or organic food. Journal of International Consumer Marketing, 27, 295-306.

Haws, K., Winterich, K. P., \& Naylor, R. W. (2014). Seeing the world through green-tinted glasses: Green consumption values and responses to environmentally friendly products. Journal of Consumer Psychology, 24, 336-354.

Hayes, A. F. (2018). Introduction to mediation, moderation, and conditional process analysis: A regression-based approach. The Guilford Press.

Krishna, A., Cian, L., \& Aydınoğlu, N. Z. (2017). Sensory aspects of package design. Journal of Retailing, 93, 43-54.

Kyung, E. J., Thomas, M., \& Krishna, A. (2017). When bigger is better (and when it is not): Implicit bias in numeric judgements. Journal of Consumer Research, 44, 62-79.

Lam, S. Y., \& Mukherjee, A. (2005). The effects of merchandise coordination and juxtaposition on consumers' product evaluation and purchase intention in store-based retailing. Journal of Retailing, 81, 231-250.

Lin, C. \& Shih, L. (2016). Effects of different packages on food product contagion: The moderating roles of mood states and product related information. Journal of Consumer Behavior, 15, 163-174.

Magnier, L., Schoormans, J., \& Mugge, R. (2016). Judging a product by its cover: Packaging sustainability and perceptions of quality in food products. Food Quality and Preference, 53, 132-142.

Marckhgott, E., \& Kamleitner, B. (2019). Matte matters: When matte packaging increases perceptions of food naturalness. Marketing Letters, 30, 167-178.
Marozzo, V., Raimondo, M. A., \& Miceli, G. (2020). Effects of au naturel packaging colors on willingness to pay for healthy food. Psychology \& Marketing, 37, 913-927.

Martin, I. M., \& Stewart, D. W. (2001). The differential impact of goal congruency on attitudes, intentions, and the transfer of brand equity. Journal of Marketing Research, 38, 471-484.

Mishra, A., \& Mishra, H. (2010). Border bias: The belief that state borders can protect against disasters. Psychological Science, 21, 15821586.

Morales, A., \& Fitzsimons, G. (2007). Product contagion: Changing consumer evaluations through physical contact with "disgusting" products. Journal of Marketing Research, 44, 272-283.

Murdoch, J., \& Miele, M. (2004). A new aesthetic of food? Relational reflexivity in the "alternative" food movement. In M. Harvey, A. McMeekin \& Alan Warde (Eds.), The qualities of food. Alternative theories and empirical approaches (pp.156-175). Manchester University Press.

Newman, G. E., \& Dhar, R. (2014). Authenticity is contagious: Brand essence and the original source of production. Journal of Marketing Research, 51, 371-386.

Ode, A., Fry, G., Tveit, M. S., Messenger, P., \& Miller, D. (2009). Indicators of perceived naturalness as drivers of landscape preference. Journal of Environmental Management, 90, 375-383.

Patrick, V. M., Atefi, Y., \& Hagtvedt, H. (2017). The allure of the hidden: How product unveiling confers value. International Journal of Research in Marketing, 34, 430-441.

Perry, R. (2014). Here's the definitive proof that you should never go to Starbucks for 'fresh baked' goods. Retrieved May 11, 2020 from https://uproxx.com/viral/starbucks-fresh-baked-goods/

Reich, B. J., Beck, J. T., \& Price, J. (2018). Food as ideology: Measurement and validation of locavorism. Journal of Consumer Research, 45, 849-868.

Rivaroli, S., Baldi, B., \& Spadoni, R. (2020). Consumers' perception of food product craftsmanship: A review of evidence. Food Quality and Preference, 79, 1-11.

Román, S., Sánches-Siles, L. M., \& Siegrist, M. (2017). The importance of food naturalness for consumers: Results of a systematic review. Trends in Food Science \& Technology, 67, 44-57.

Romero, M., \& Biswas, D. (2016). Healthy-left, unhealthy-right: Can displaying healthy items to the left (versus right) of unhealthy items nudge healthier choices? Journal of Consumer Research, 43, 103 112.

Rozin, P. (2005). The meaning of "natural" process more important than content. Psychological Science, 16, 652-658.

Rozin, P. (2006). Naturalness judgments by lay Americans: Process dominates content in judgments of food or water acceptability and naturalness. Judgment and Decision making, 1, 91-97.

Rozin, P., Spranca, M., Krieger, Z., Neuhaus, R., Surillo, D., Swerdlin, A., \& Wood, K. (2004). Preference for natural: Instrumental and ideational/moral motivations, and the contrast between foods and medicines. Appetite, 43, 147-154.

Rozin, P., Fischler, C., \& Shields-Argeles, C. (2012). European and American perspectives on the meaning of natural. Appetite, 59, $448-455$

Sample, K. L., Hagtvedt, H., \& Brasel, S. A. (2020). Components of visual perception in marketing contexts: A conceptual framework and review. Journal of the Academy of Marketing Science, 48, 405421.

Schösler, H., de Boer, J., \& Boersema, J. J. (2013). Organic food philosophy: A qualitative exploration of practices, values, and beliefs of Dutch organic consumers within a cultural-historical frame. Journal of Agricultural and Environmental Ethics, 26, 439-460.

Schroll, R., Schnurr, B., \& Grewal, D. (2018). Humanizing products with handwritten typefaces. Journal of Consumer Research, 45, 648672. 
Sevilla, J., \& Townsend, C. (2016). The space-to-product ratio effect: How interstitial space influence product aesthetic appeal, store perception and product preference. Journal of Marketing Research, 53, 665-681.

Siegrist, M., \& Sutterlin, B. (2017). Importance of perceived naturalness for acceptance of food additives and cultured meat. Appetite, 113, 320-326.

Smith, R. K., Newman, G. E., \& Dhar, R. (2016). Closer to the creator: Temporal contagion explains the preference for earlier serial numbers. Journal of Consumer Research, 42, 653-668.

Staub, C., Michel, F., Bucher, T., \& Siegrist, M. (2020). How do you perceive this wine? Comparing naturalness perceptions of Swiss and Australian consumers. Food Quality and Preference, 79, 103752.

Tveit, M., Ode, Å., \& Fry, G. (2006). Key concepts in a framework for analysing visual landscape character. Landscape Research, 31, 229 255.

Van Osselaer, S. M. J., \& Alba, J. W. (2000). Consumer learning and brand equity. Journal of Consumer Research, 27, 1-16.

White, K., Lin, L., Dahl, D. W., \& Ritchie, R. (2016). When do consumers avoid imperfections? Superficial packaging damage as a contamination cue. Journal of Marketing Research, 53, 110-123.

World Economic Forum (2016). More plastic than fish in the ocean by 2050. Retrieved May 11, 2020 from https://www.weforum.org/ press/2016/01/more-plastic-than-fish- in-the-ocean-by-2050-reportoffers-blueprint-for-change/.

Ye, N., Morrin, M., \& Kampfer, K. (2020). From glossy to greasy: The impact of learned associations on perceptions of food healthiness. Journal of Consumer Psychology, 30, 96-124.

Zampini, M. \& Spence, C. (2004). The role of auditory cues in modulating the perceived freshness and staleness of potato chips. Journal of Sensory Studies, 19, 347-363.

Zero Market (2019). Retrieved November 20, 2019 from https://www. thezeromarket.com/

Zhao, M., Lee, L., \& Soman, D. (2012). Crossing the virtual boundary: The effect of task-irrelevant environmental cues on task implementation. Psychological Science, 23, 1200-12007.

Zhou, L., Yang, Z., \& Hui, M. K. (2010). Non-local or local brands? A multi-level investigation into confidence in brand origin identification and its strategic implications. Journal of the Academy of Marketing Science, 38, 202-218.

Publisher's note Springer Nature remains neutral with regard to jurisdictional claims in published maps and institutional affiliations. 